\title{
Critical Thinking and the Use of Optical Illusions
}

\author{
James M. Hoefler, Dickinson College
}

The greatest thing a human soul ever does in this world is to see something, and tell what it saw in a plain way. Hundreds of people can talk for one who can think, but thousands can think for one who can see. To see clearly is poetry, prophecy, and religion, all in one.

John Ruskin, Modern Painters ${ }^{1}$

\section{Overview}

The ability to think critically-to "see clearly"-is a skill that has generated a great deal of interest and attention among educators in recent years. ${ }^{2}$ One annotated bibliography of works published since 1980 cites over 900 monographs and articles on critical thinking (Cassel and Congleton 1993). The swath of disciplines represented by this body of literature is broad, and all levels of education are involved, from kindergarten and high school to post-secondary education ${ }^{3}$ and graduate-level programs. A center for critical thinking has been established at Sonoma State University to advance understanding and application of this mode of inquiry. The number of professional conferences devoted to this subject seems to be on the rise, as well.

With only a few exceptions, however, political scientists have not contributed significantly to the conversation about critical thinking, even though the nature of the subject matter they typically deal with seems ideally suited to the tack. ${ }^{4}$ Perhaps political scientists are missing an opportunity by not thinking and writing more consciously about how critical thinking could enhance the learning that goes on in their classrooms.

\section{Critical Thinking Explained}

Though critical thinking has no universally accepted definition, common threads run through most uses of the concept.
- First, critical thinking typically connotes an appreciation for the various approaches to understanding that differing intellectual perspectives provide, both within and across disciplines.

- Second, critical thinking usually involves increasing one's sensitivity to culturally and sociologically based differences.

- Challenging students to identify and reconsider some of their basic, usually unacknowledged assumptions about the way the world should-and does-work is a third characteristic of the critical-thinking orientation.

Combined, these elements of critical thinking form the core of an approach to learning that encourages students to step outside themselves to assess phenomena through a variety of analytic lenses.

There is one more thing about critical thinking that most practitioners would tend to agree on: it is not easy to foster in students (Paul 1992 , iii). This is the case because critical thinking requires students to question something they may have a great deal of confidence in: their innate ability to interpret accurately the things they see, feel, hear and read. 5 Teachers must somehow convince students that receptors and processors of information are not infallible. Indeed, getting students to suspend trust in their innate ability to see the world as it is may be the most important step they can take in developing the analytic dexterity required to think critically about the truth-or in most cases, truths--that exist in the world.

\section{Classroom Experiences}

Academics can get students to think critically in a number of ways. One method involves requiring students to prepare for a debate without revealing ahead of time which side they will be asked to defend. If the debate question is reasonably well formulated, students are forced to appreciate the logic and evidence that undergird each of two competing positions. In the process, students must grapple with two truths instead of one.

Critical thinking also can be advanced simply by incorporating competing perspectives into readings, lectures, and discussions. This might mean including a Marxist interpretation of interest group power in an American government classroom alongside more mainstream interpretations. Introducing a feminist perspective to a discussion of public policies involving reproductive rights would accomplish the same sort of end in a policy analysis course. And a course on foreign policy or diplomacy is a logical place to deal with the business of understanding how the words and actions of individuals in one country have the potential for being misinterpreted in another.

Critical thinking also can be fostered through interdisciplinary programs that bring various bodies of literature and methodologies to bear on important policy questions of the day. Humanists schooled in the study of ethics and moral philosophy can help political scientists and their policy students develop insights into the values that frame policy decisions. The social sciences-economics, history, and sociology, for example-can provide an important context for better understanding policy as well. Technology assessment, probability theory, and empirical data generated by the natural sciences-all thought generally to lie outside mainstream political science considerationsalso may be able to help students shine a different light on policy analysis.

Ultimately, the point of turning to interdisciplinary and cross-methodological studies is to get students used to--and comfortable with- 
the idea of approaching phenomena from differing perspectives. In the end, such exercises in critical thinking have the potential to empower students to look beyond themselves, beyond single reference sources, and beyond homogenous bodies of literature to sketch a more comprehensive, threedimensional picture of reality than can be generated otherwise.

\section{International Relations}

The emerging global economy and an increasingly interdependent world order both make learning to become sensitive to cultural differences more important than ever for students of public policy and international economy. The meaning of a word, a smile, a bow, or a handshake may well mean one thing in one culture, and something quite different in another culture. When parties to cross-cultural interactions fail to think critically about those interactions, problems are bound to arise. ${ }^{6}$

Actions taken by President George Bush, U.S. emissary to Iraq April Glaspie, and Iraq's President Saddam Hussein provide a good, specific example of this lack of cultural sensitivity at work in the international relations context. Bush took a firm stand with Hussein after Iraq invaded Kuwait, demanding that Iraqi forces withdraw from Kuwait forthwith. This, after Glaspie reportedly informed Hussein (on hearing of his complaints about Kuwaiti behavior), that the situation was, in the eyes of U.S. leaders, "an Arab problem" (Rosenthal 1990). Apparently, the U.S. meant to communicate to Hussein that the West would prefer that Arabs hammer out a diplomatic solution on their own, while Hussein apparently took these words to mean that Iraqi forces would be allowed to advance on Kuwait with impunity.?

This original miscommunication was compounded by Bush's tough talk after the fact: talk that was intended, it is presumed, to scare Hussein into withdrawing from $\mathrm{Ku}$ wait, which Iraqi troops by then had invaded. From Hussein's per- spective, such diplomatic tweaking was a slap in the face, posturing that only seemed to strengthen Hussein's resolve (Freidman 1990; Lewis 1990; Rosenthal 1990). Ironically, President Bush said on numerous occasions that Saddam just did not seem to understand how firmly the United States was committed to using force, while it was Bush who did not seem to understand how much more firm the resolve of Hussein became with each new rattle of American sabers. No one can say for sure, of course, but a little critical thinking may have gone a long way toward avoiding altogether the conflict involving Iraq, Kuwait, the United States, and its allies.

In the end, it is not that Hussein was right to invade Kuwait and Bush was wrong to order troops into action in response. The errors critical thinking identifies have to do with interpretation. Glaspie and her superiors were wrong in not understanding that her behavior would be viewed as a green light to Hussein. If they had, they may have been able to ward Hussein off quietly before the invasion of $\mathrm{Ku}$ wait took place. For his part, Hussein was wrong in not appreciating how vital-geopolitically and economically-Kuwait was perceived to be to U.S. interests. If he had, he might have anticipated that the West would probably not allow his invasion to stand.

And George Bush was wrong to think that public humiliation was the way to get Hussein to back off. Certainly, by the time the air war started in January of 1991, Hussein had to know he would be beaten badly by the allied forces. He understood Bush's strong stance completely, no doubt; it's just that at that point, he did not care. Backed into a corner, he preferred to come away from Kuwait a bloodied loser rather than a humiliated coward. For him, standing his ground in Kuwait was entirely rational, even though his behavior was portrayed by Westerners as being entirely irrational.

\section{Legislative Process}

Deborah Tannen, author of You Just Don't Understand, talks about "genderlicts" in her best-selling treatment of the differences between the way men and women communicate with each other. It is not as if one mode of communication is "wrong" and the other "right," a point she makes repeatedly throughout the book. Rather, critical thinking demands that senders of messages attempt to assess how those messages might be received, given the receiver's frame of reference. At the same time, it becomes incumbent on the receiver to attempt to appreciate the meaning of the message, as understood from the sender's frame of reference.

On the one hand, if both sender and receiver are responsible critical thinkers, the chances of miscommunication drop precipitously. On the other hand, however, if either the sender or the receiver is not sensitive to the possibilities of misinterpretation, the chances for miscommunication escalate dramatically. A recent incident involving the treatment of women before the Judiciary Committee of the U.S. Senate provides a good example of just this sort of miscommunication.

On September 18, 1990, the Judiciary Committee took its fourth day of testimony regarding Judge David Souter, nominated by then-President George Bush to fill the Supreme Court vacancy created by retiring associate justice William Brennan. On that day, Molly Yard, then-president of the National Organization for Women, took part in a panel presentation made by six women who appeared in opposition to the Souter nomination. ${ }^{8}$

An interesting exchange took place at these hearings involving, primarily, Ms. Yard and Senators Strom Thurmond (R-SC), Alan Simpson (R-WY), and chairperson of the committee Joseph Biden (D$\mathrm{DE})$. The situation began when it came time for Strom Thurmond to cross-examine the assembled witnesses. He started and ended with: "Mr. Chairman, we've got a lovely group of ladies here. We thank you for your presence. I have no questions." 
A few minutes later, Senator Alan Simpson made the following comments and observations during his interrogation of the panelists:

... If you support unlimited abortion rights, I do think you do a disservice to the cause we share: to insure that women do have this freedom to choose. Because even Roe versus Wade-Don't shrug, I see that all the time. I get tired of watching shrugs and kind of looking up at the ceiling when Strom Thurmond says something courteous and there's that "ugh"- -and that one too. You know let's just stay in this picture and, and just listen for a minute and maybe that wouldn't be an untoward or, or maybe it might even be a courteous thing to do, without casting a glance and a shrug and a "Who are these boobs?" and "How did they not listen to what we say to them?" and "Can't they hear us?" That's a tiresome arrogance. So, Roe versus Wade presents limits on abortion, ladies, such as when. ...

Simpson continued on to ask a question of the witnesses, and Ms. Yard went on to reply to the substance of the question, before adding:

... and through you, if I might, apologize to Strom Thurmond if he didn't like my glances, but we are greeted every time we come before him as: "Ladies you are all so attractive." Somehow, it does not sit well. Maybe you could explain to him that we would like to be treated the way you treat everybody else. You don't say to men "Gentlemen, you all look lovely."

The following exchange ensued:

Simpson: Well, you know, we don't have to quack around in that stuff.

Yard: I wish you would explain it to him because it doesn't do him any good.

Simpson: He's a man of great civility, and a Southern gentleman of the first order and if you don't like the way he expresses himself, what business is that of yours, you ought not to roll your eyes at it-

Biden: Maybe we could kinda move on and, ah, I'm not being facetious when I say I think maybe it would be useful for us to get to the issue if we could.

This exchange is important be- cause it presents two clearly opposing views of what was happening in the Senate hearing room. For the men, it seems, the women were being overly sensitive, apparently more concerned with the way they were being treated on a personal level than they were with the substance (as the men perceived that substance) of the issues at hand. Simpson, in particular, thought it inappropriate to "quack around in that stuff." And Biden, in an attempt to diffuse an escalating confrontation that apparently he thought to be an irrelevant digression, interrupted as the chair, arguing that "maybe it would be useful for us to get to the issue."

For the women, the way they were being treated was the issue, inseparable from the argument that they were making about Souter, more generally. They seemed frustrated, and even offended, by what for them was a patronizing and inappropriate greeting made by Senator Thurmond. That greeting signaled to the women that neither they nor their positions were being seriously considered. Clearly, Simpson was not in touch with the message Thurmond sent-intentionally or not-to the panelists. Nor, apparently, was Biden, for he seemed to see the exchange between Simpson and Yard as being off track when, in the women's eyes, it was symptomatic of the larger societal problems that these women had come to testify about.

The insensitivity on the part of these senators came back to haunt the entire committee a year later when its members decided, as a group, not to pursue allegations made by Anita Hill that she had been sexually harassed by another nominee to the high court: Clarence Thomas. Insensitivity was also manifest in the way that Simpson and the committee's lead crossexaminer for the Republicans, Arlen Specter (R-PA), treated Hill as a witness. Many women were outraged at the behavior of Simpson and Specter, both of whom later issued public apologies for their conduct.

The seemingly insensitive treatment of women by members of the Judiciary Committee had broad im- plications for the nature of representation manifest in the U.S. Senate. The backlash from women nearly cost Specter his senate seat in Pennsylvania when an upstart Democrat, Lynn Yeakel, fell only a few percentage points short of unseating the two-term incumbent in 1992.

More generally, record numbers of women ran for elected office that same year and six new women were swept into the Senate (bringing the total to an all-time high of eight). ${ }^{9}$ Now Simpson and Specter have two new colleagues on the Judiciary Committee: Diane Feinstein (D-CA) and Carol Moseley Braun (D-IL). ${ }^{10}$ Deborah Tannen (1991) was even retained to conduct a seminar designed to provide the senators with insight into the way male representatives were being perceived by women. ${ }^{11}$

\section{Persuasion in the Courtroom}

Differing perspectives between cultures led to problems in the Persian Gulf, and differing perspectives between genders led to changes in the nature of representative government in the U.S. Senate. We now move to differences in perspective that arise from the use and manipulation of video technology. Patricia Greenfield, professor of psychology at University of California-Los Angeles, and Paul Kibbey, a second-degree black belt in aikido, have written about how strategic use of media technology can distort the truth and mislead viewers. They use the videotape made of Rodney King's arrest on a Los Angeles street as a case in point.

Admittedly, an untampered viewing of the tape itself has the potential to illicit different responses from people depending on any number of personal characteristics, including (potentially) race, gender, and ideology. Personal experiences may also color one's interpretation. But it is even more important for the critical thinker to realize that the same individual might view the tape differently depending on the techniques used in the tape's presentation. For example, Greenfield 
and Kibbey argue that slowing the motion down tends to lessen the impact of the blows in the viewer's eyes. In their own words, "slow motion minimizes the violence. In the real world, a faster blow is a harder blow; a slower blow is softer. In the tape, slow motion makes the blows appear less harmful than they really were." Slow motion also makes the film seem unreal. As one individual who viewed the tape in slow-motion noted, "it looks like a ballet ... it's definitely easier to watch this", (in Greenfield and Kibbey 1993).

Sound is another source of data that can add to, or detract from, the impact of the tape. Greenfield and Kibbey point out that when slowed down, sound is eliminated so that one does not hear the batons hitting the mark, or the screams of the target. Use of freeze-frame can be used to distort meaning as well. Rodney King's raised arm in freeze-frame may appear as a threatening motion, but when put in the context of the blow that preceded it, it may be clear that the raised arm was a reaction of self-defense. Just as a sentence can be taken out of context to distort the intended meaning, a frame of video can be shown out of context for the same purpose. Repeated showings also can desensitize the viewer to the point where, according to Greenfield and Kibbey, "the beating appears less troubling, less violent, [and] less excessive."

On its face, videotape seems to present very little in the way of critical thinking challenges. Indeed, the use of slow motion and freezeframe might appear, at first, as a straightforward means of enhancing the evidence record as jurors strive to discern the reality of a videotaped situation. But Greenfield and Kibbey make it clear that critical thinking is important-maybe even more important - when videotape is in play, precisely because of general predispositions to believe the video record, uncritically.

\section{Getting Started}

Critical thinking is required to process information accurately in each of the three examples laid out above. Despite its great potential value, however, and despite the best efforts of well-intentioned advocates, critical thinking is not easily taught precisely because it requires students to call into question something they may find to be beyond doubt: their own ability to "see clearly." If there were a way to broach the concept and demonstrate it in a nonthreatening, and maybe even entertaining, way, the application of critical thinking to more serious course materials might be facilitated.

There are, no doubt, any number of ways to get students to take that first step off the firm ground represented by what they think they might know into the world of thoughtful, purposeful circumspection. One exercise that seems to engage students and brings home the importance of generating in the self a sense of humility about one's innate ability to perceive the world accurately and sensitively involves the use of optical illusions.

Clearly sight is one of the senses we rely on most as we navigate through life. And it is one of the most dependable. But as every magician knows well, the eyes are susceptible to deception. If, in the classroom, students can see how easy it is for their own eyes, as processors of information, to play tricks with reality, it becomes easier for them to see how other filters of information-gender, social class, culture, ideology, academic discipline, and methodological biases, to name a few-can skew and sometimes even transform reality in the mind's eye.

In short, going through the optical illusion exercise laid out below can make students more willing, more able, and maybe even more likely to suspend their own assumptions, mindsets, ideologies, and cultural frames of reference when attention turns to more serious subjects. Seeing how a set of apparently innocuous images can play havoc with the brain has a potentially liberating effect on the students' thinking. It forces the student to confront the question: "If my eyes can deceive my brain so easily, cannot the brain be tricked in other ways?"

\section{Type I Illusions: Multiple Valid Interpretations}

The optical illusions exercise involves two types of illusions. With Type I illusions, students are exposed to some simple sketches that could be "interpreted" in two or more different ways. ${ }^{12}$ In this phase, I present some classic illusions, along with some that are more obscure, to illustrate how easy it is to make the snap judgment that there is really only one way to see a phenomenon when in reality there are two, or in some cases even more.

This part of the exercise is wrapped up by having the students generate-either as a class or in small groups-a set of lessons or proverbs that flow from their experiences with multiple valid interpretations. The "morals" the students would be expected to glean include the following:

Moral \#1a: Despite first impressions, more than one interpretation can be made of reality.

Moral \#1b: Alternative interpretations can be as legitimate as the original; there may be no "truth" to be found in the sense that one interpretation is "right" and others are "wrong."

Moral \#1c: It may be difficult to see alternative interpretations, at times; it takes effort on the part of the viewer.

Moral \#1d: When the viewer ceases the effort to see the alternative view, the ability to see more than one view also ceases (often, the image returns to the original mind's-eye interpretation). In more generic terms, seeing an alternative explanation does not inoculate the viewer from taking a parochial view of the world; one may have to keep trying to see that second, or third, or fourth interpretation. And when one stops trying, the world begins to look the same as it did before the attempt was made.

Moral \#1e: It is very difficult-in some cases, maybe even impossible-to see more than one worldview at the same instant. In addi- 
Type I Illusions: Multiple Valid Interpretations

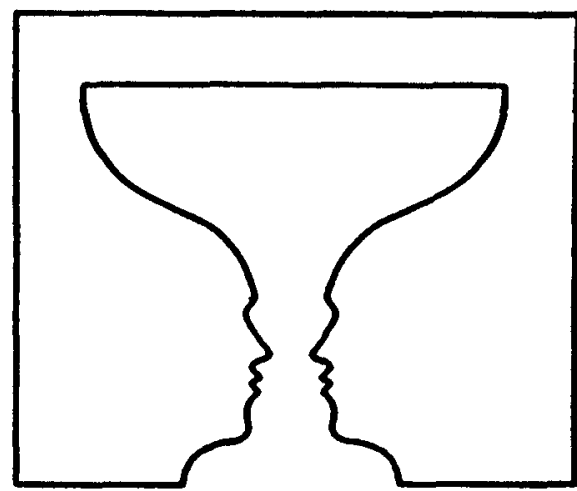

The classic: "chalice or opposing silhouettes" (Zakia 1979, 24).

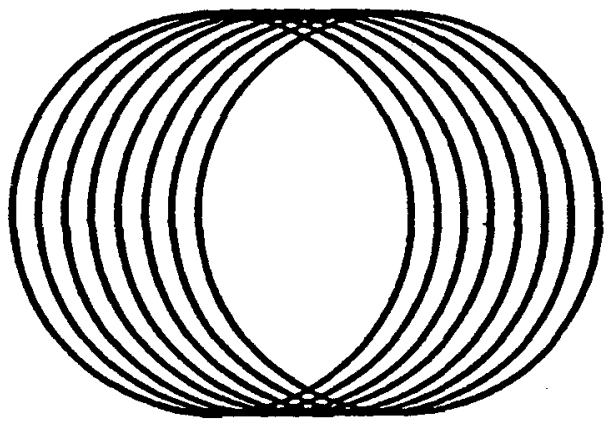

To move through this slinky would you move from left to right, or right to left? Blinking alternate eyes open and closed will help cause this image to "reverse" (Luckiesh $1965,70)$.

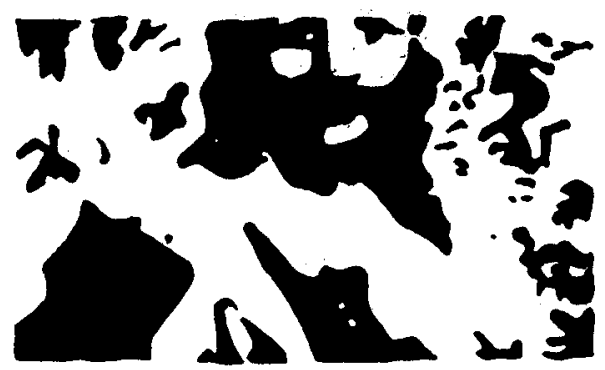

Random black and white splotches or does a likeness of Jesus appear (Bloomer 1976, 40)?

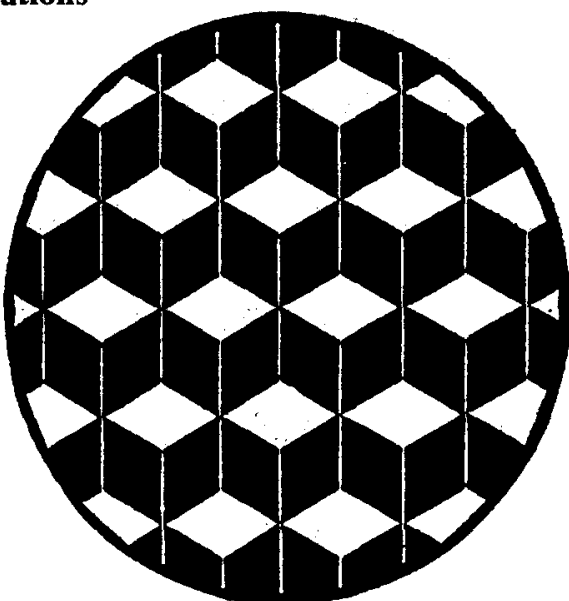

Looking down on the white tops of cubes, looking up at the white bottoms, or simply chains of white diamonds (Luckiesh 1965, 68)?

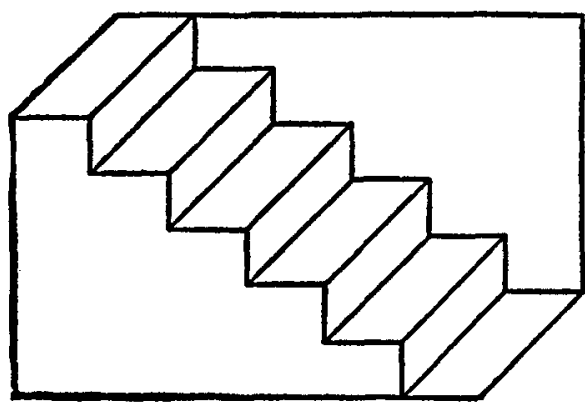

Are you looking down on the tops of these stairs (the obvious interpretation)? Or are you looking at the underside of a set of stairs? To see this alternative view, imagine that the open white space at the upper right is closer to you and the open white space at the lower left is further away from you (Luckiesh 1965, 70).

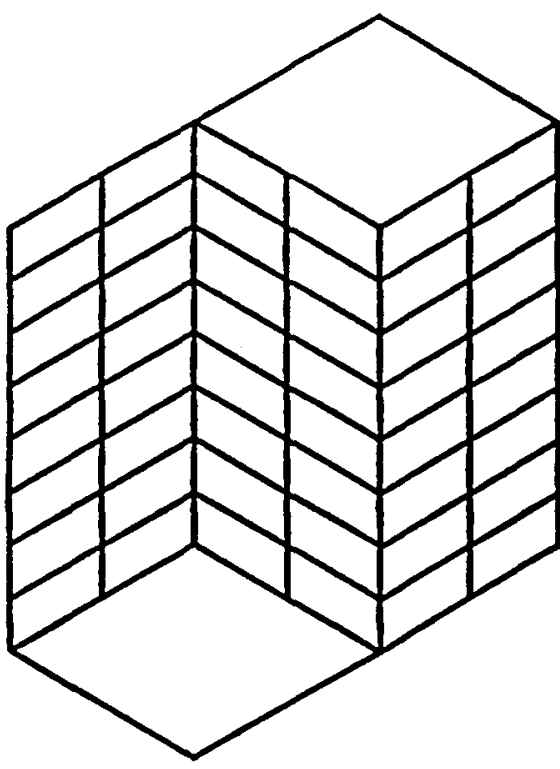

Are you looking down on the open white space, or up at it? Or looking down on one open white space and up at the other (Luckiesh 1965, 71)?

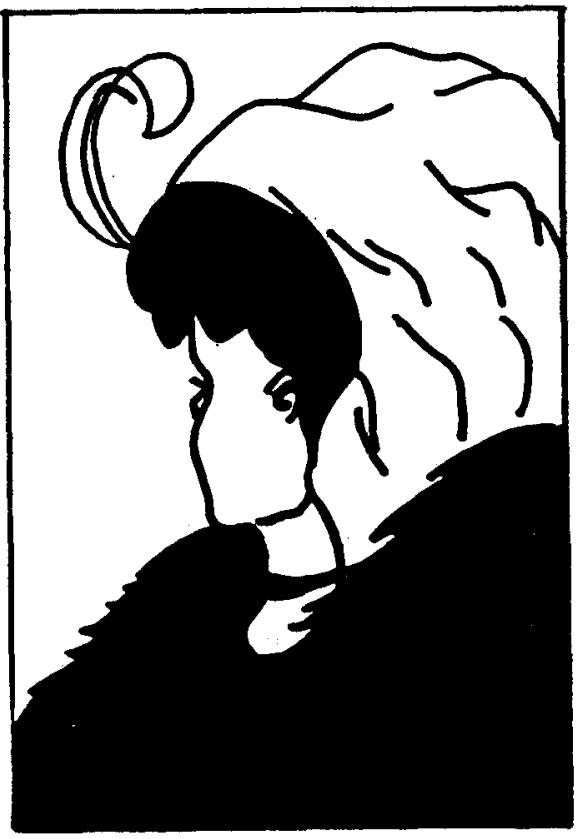

An old woman looking down and left, or a young woman looking left and away from the viewer (Bloomer 1976, 44)? 
tion to realizing that multiple mindsets exist, students must become facile in jumping back and forth between mindsets.

\section{Type II Illusions: Deceptive Appearances}

In the second part of the exercise, a different kind of optical illusion is used to generate a second set of morals. Here, viewers tend to interpret the illusions inaccurately at first. Lines in one illusion appear curved when, in reality, they are straight. Lines in another illusion appear to be different lengths when in fact, they are the same length. Another illusion appears to consist of a single spiral line that is, in fact, a set of concentric circles.

Once again, the exercise culminates when the students are asked to draw a series of lessons out of their experience. These "morals" might include:

Moral \#2a: Not only might there be more than one way to look at something, one way-the way most would tend to see a phenomenon at first-may turn out to be demonstrably erroneous.

Moral \#2b: Appreciating context is the key to interpretation. Viewers make erroneous conclusions because the context of the image distorts perceptions of reality. This context-the converging lines, the angled arrows, the strategically placed crosshatching-is analogous to the cultural and value frames that serve as filters (and distorters) of information that we process.

Moral \#2c: To get closer to the truth, the viewer may have to depend on "external points of reference" that are not as susceptible to faulty interpretation. For optical illusions, a straight-edge, a compass, or a ruler might do. In the real world of applied critical thinking, second opinions of disinterested parties or empirical data (quantitative or qualitative in nature, fairly collected and interpreted) may serve the same purpose. In the end, of course, there will probably be no simple route to truth, no straight edge that will yield an uncontestable interpretation of reality. Still some interpre- tations are better than others-and, as with this set of illusions, some interpretations are clearly wrongand that reality has to be appreciated.

Moral \#2d: There is no easy way to know, in the real world, if you are dealing with a Type I situation (multiple valid interpretations) or a Type II situation (deceptive appearances). In the end, critical thinking is required to get one started down the road toward making that kind of determination. The great challenge for the critical thinker, then, is to understand that snap judgments-the product of base instincts and natural predispositions -may be responsible for creating one of two scenarios. First, the uncritical snap judgment one arrives at initially may be one of several equally valid interpretations. Second, the uncritical interpretation of a phenomenon may be altogether invalid. Ultimately, in addition to learning what snap judgments might be, the critical thinker learns to appreciate what seat-of-the-pants, uncritical interpretations are probably not: incontestably correct.

Type II Illusions: Deceptive Appearances
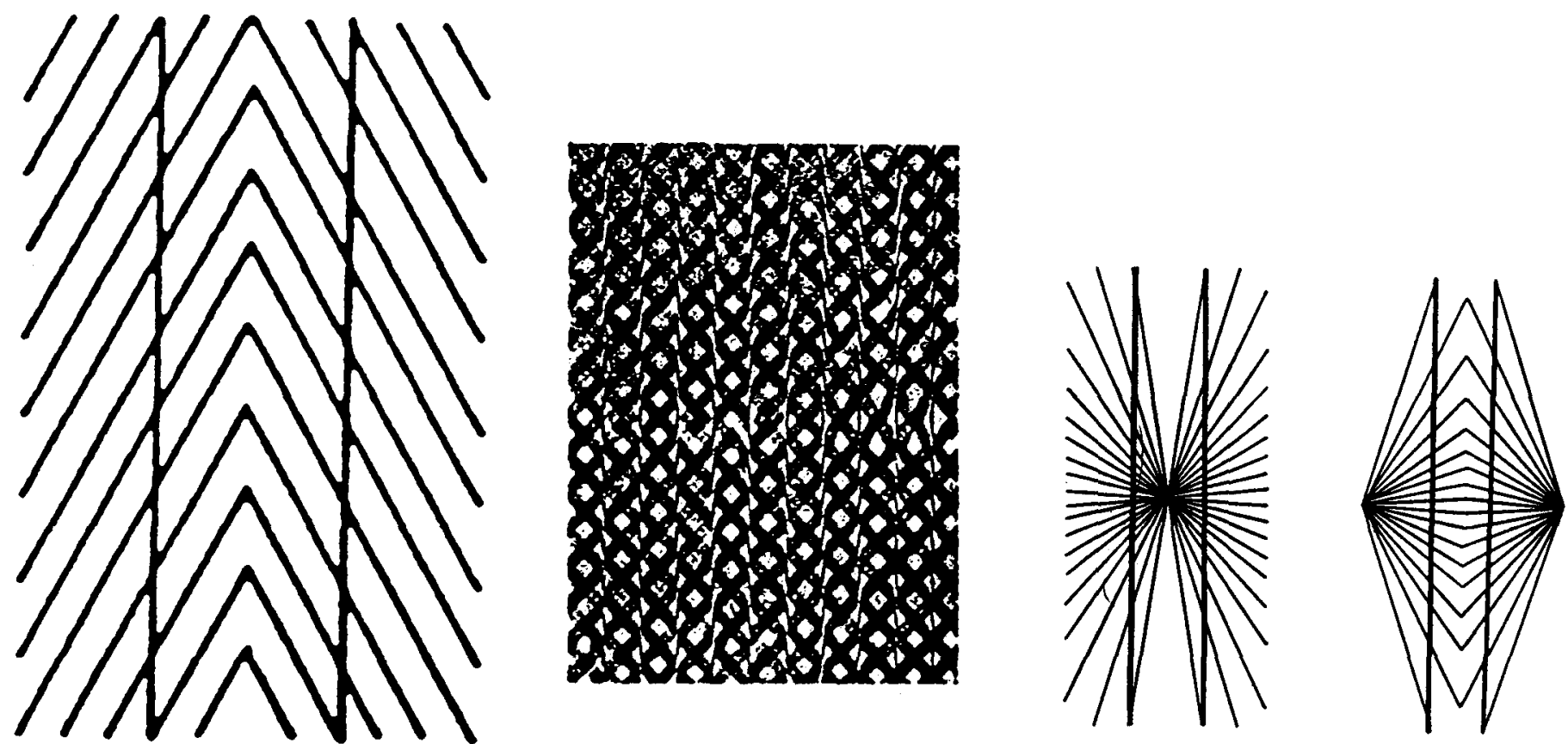

The vertical lines in all three depictions are really perfectly straight and parallel, even though they do not appear to be (Luckiesh 1965, 89; Coren \& Girgus 1978, 50; Bloomer 1976, 48). 
Type II Illusions: Deceptive Appearances (continued)
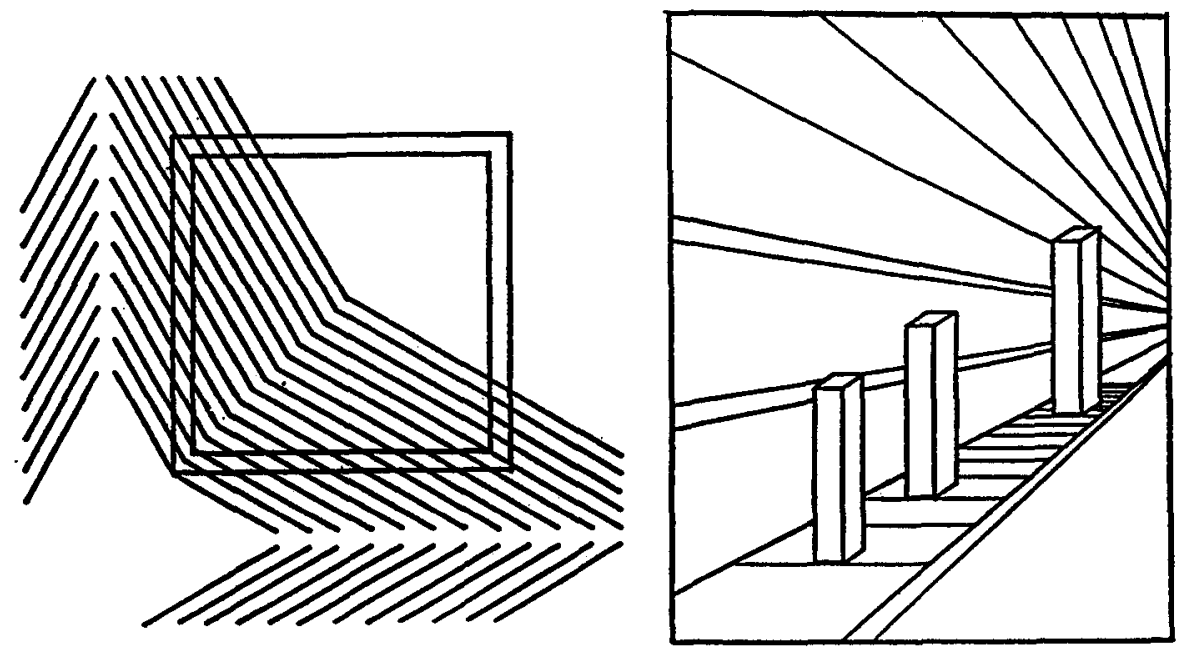

Is this shape a perfect square, or is it skewed a bit? In fact, it is a perfect square (Luckiesh 1965, 61).

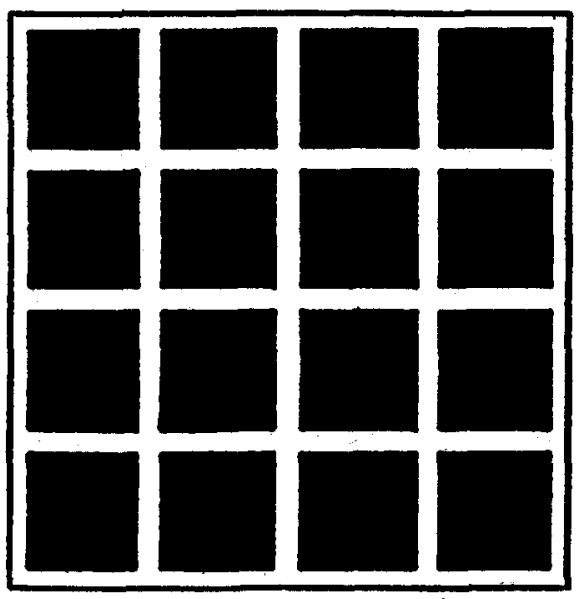

Staring at this illusion makes one see grey, blurry blobs at the white intersections. No grey blobs exist (Luckiesh 1965, 118).

\section{Summary}

There is really no end to the potential for applying critical thinking in political science. Indeed, some advance critical thinking as a way of life. It is clear that some method is required to bring students into contact with the world outside their own unchallenged perceptions of it. Critical thinking may not prove to be the best means to that end, but it is at least a reasonable means to it. And the use of optical illusions can get one started on the path
Which is the tallest building? The one on the right may appear taller but all three are the same height (Luckiesh 1965, 60).

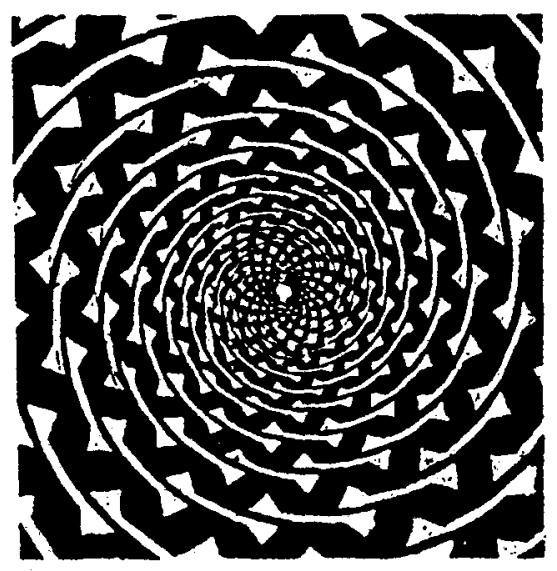

Does the swirling white line appear to be a spiral? The white lines are actually a series of concentric

toward that serious and important goal of helping students in the political science classroom do what John Ruskin values so dearly-see clearly-while maybe even having some fun along the way.

\section{Notes}

1. Thanks to Professor Bill Jefferies for the John Ruskin quote and to Bob Cavenagh for leads on optical illusions. Thanks also to Dickinson College's Policy Studies students, who have helped me rethink and refine my ideas about critical thinking over the years. circles (Luckiesh 1965, 89).
2. Experiments in the Development of Critical Thinking, published by Edward Glaser in 1941, and "A Concept of Critical Thinking," published by Edward Ennis $(1962,81-111)$ in the 1962 volume of the Harvard Educational Review, are regularly cited as the modern, seminal works in this area, although critical thinking's intellectual roots trace back to the pedagogy of Socrates.

3 . In one notable example, the 19-campus California state university system instituted a graduation requirement in critical thinking in 1988 (Paul 1992, 1).

4. Although one recent article published in PS deals specifically with critical thinking (Cohen 1993, 241-44), only six of the 930 articles abstracted by Cassel and Congleton have a significant political science dimension.

5. Typical college students may feel challenged only by the things they clearly do not understand. Critical thinking requires that students also consider being challenged by the things they think they do understand. In many ways, this is a more difficult endeavor, for students may realize in short order the effort required to master some complex academic abstraction, but may be much less willing to invest time and effort in reconsidering things that, from their perspective, are pretty well understood.

6. In Japan, for instance, the world haimeaning yes - does not imply agreement (as Westerners often interpret it). Instead, use of hai in Japan is meant to acknowledge that the speaker has been heard and that the listener is contemplating a reply (Hatsumi 1993). A Westerner who fails to appreciate the significance of this alternative understanding may walk away from a meeting with a Japanese negotiator thinking that agreement had been reached, when all the negotiating counterpart meant to do was indicate that the message was received.

7. Given the status of women in most countries of the Middle East, it also could be argued that simply having a woman deal with Hussein may have sent Hussein the message that the situation between Iraq and Kuwait was not viewed as particularly important to the United States.

8. Kate Michelman, executive director of the National Abortion Rights Action League, Fay Wattleton, president of Planned Parenthood, and Eleanor Smeal, president of the Fund for the Feminist Majority, were also among the panelists.

9. The number of women in the Senate increased to nine after Kay Bailey Hutchinson won a special election in socially conservative Texas to serve out the remainder of Senator Lloyd Bentson's term when Bentson was tapped to be the treasury secretary in the incoming Clinton administration. The House of Representatives (now with 47 women, up from 29 in 1991) exhibited a dramatic increase in female representation as well.

10. Braun's appointment to the committee is especially poignant because she, like Yeakel, attributed her interest in running for the Senate in the first place to the outrage she felt over the way Anita Hill was treated by the men who were now her Judicial Committee colleagues.

11. Even the military is showing signs of 
strain and change along these lines. The inability of men in the chain of command to appreciate the charges brought by women who claimed to have been sexually molested at a Tailhook convention led to the early retirement, resignation, and sanctioning of several high-ranking officials in the Department of the Navy. Now women are being trained as combat pilots in the Air Force, the first branch of the military ever to be led by a female service secretary.

12. I use overhead projections rather than handouts so that I can control the presentation. With handouts, students tend to skip ahead so that the whole class is not looking at the same illustration simultaneously, and those who are having trouble seeing an illustration in more than one way can feel left behind.

\section{References}

Bloomer, Carolyn M. 1976. Principles of Visual Perception. New York: Van Nostrand Reinhold.

Cassel, Jeris F., and Robert J. Congleton. 1993. Critical Thinking: An Annotated Bibliography. Metuchen, NJ: Scarecrow Press.

Cohen, Mel. 1993. "Making Critical Thinking a Classroom Reality." PS 26.
Coren, Stanley, and Joan Stern Girgus. 1978. Seeing Is Deceiving: The Psychology of Visual Illusions. Hillsdale, NJ: Lawrence Erlbaum Associates.

Ennis, Edward. 1962. "A Concept of Critical Thinking." Harvard Educational Review 32.

Freidman, Thomas L. 1990. “A Dreamlike Landscape, a Dreamlike Reality." New York Times, 28 October.

Glaser, Edward M. 1941. Experiments in the Development of Critical Thinking. New York: AMS Press.

Greenfield, Patricia, and Paul Kibbey. 1993. "Picture Imperfect." New York Times, 1 April.

Hatsumi, Reiko. 1993. "A Simple 'Hai' Won't Do." New York Times, 15 April.

Lewis, Flora. 1990. "Between-Lines Disaster." New York Times, 19 September.

Luckiesh, M. 1965. Visual Illusions: Their Causes, Characteristics, and Applications. New York: Dover.

Paul, Richard W. 1992. Critical Thinking: What Every Person Needs to Survive in a Rapidly Changing World, ed. A.J.A. Binker. Santa Rosa, CA: Foundation for Critical Thinking.

Rosenthal, Andrew. 1990. "Did U.S. Overtures Give Wrong Idea to Hussein?"' New York Times, 19 September.

Tannen, Deborah. 1991. You Just Don't
Understand: Women and Men in Conversation. New York: Ballantine Books.

Wade, Nicholas. 1990. Visual Allusions: Pictures of Perception. London: Lawrence Erlbaum Associates.

Zakia, Richard D. 1979. Perceptions and Photography. Rochester, NY: Light Impressions.

\title{
The Validity of Student Evaluations of Teaching
}

\author{
Laura I. Langbein, American University
}

\section{Introduction and Background}

Virtually all liberal arts colleges consider classroom teaching a major factor in evaluating overall faculty performance (Seldin 1989, 4). As of $1988,80 \%$ used systematic student ratings as all or part of the means for evaluating teaching, and that percentage had increased from $68 \%$ in just five years (Seldin 1989, 4). There is also considerable agreement that systematic student ratings are reliable. Aubrecht (1981, 1), for example, reports that previous studies of student ratings, using various internal consistency measures of reliability, "show high reliabilities-in the $.80 \mathrm{~s}$ and $.90 \mathrm{~s}$ for classes of $\mathbf{2 0}$ or more." Similarly, Cranton and Smith $(1990,207)$ also report that studies of student questionnaires "generally confirm that the questionnaire is a reliable technique."
There is considerably less agreement about the validity of systematic student ratings of college teachers. Several aspects of validity have been examined, including predictive validity (Abrami, d'Apollonia, and Cohen 1990) and face validity (Aubrecht 1981, 3; Abrami, d'Apollonia, and Cohen 1990). A third aspect of validity is construct validity. Construct validity means that student ratings, if they are to be a valid measure of the quality of teaching, should be significantly associated with variables that are theoretically expected to be predictors of quality, and the ratings should not be associated with variables that are theoretically or normatively expected to be irrelevant to teaching quality. If they are associated with normatively irrelevant variables, the ratings can be said to be "biased." For example, smaller classes are expected to, and have been shown to, produce better instruction (Glass, McGaw, and Smith 1981), so if student ratings are to have construct validity, we should observe better evaluations from students in smaller classes than in larger classes when other variables are held constant. On the other hand, there is no normative reason to expect that the sex of an instructor should be related to the quality of instruction, once variables like experience, whether the course is required, and other factors are held constant. If gender and student evaluations are associated, even when other factors are held constant, the evaluations may be biased.

Previous research on construct validity has yielded inconsistent findings. The findings appear to be highly dependent on context and methodology (Abrami, d'Apollonia, and Cohen 1990; Cashin 1988), yet 